\title{
Transdisciplinary collaboration: The future of primary health care
}

\section{Éric Contant and Kathryn Nicholson}

\section{University of Sherbrooke}

Primary care is the patient's first point of entry into the health care system, offering health care closest to where individuals live and work. Primary health care (PHC) encompasses primary care, disease prevention, health promotion, population health, and community development within a holistic framework, with the aim of providing essential community-focused health care. ${ }^{1,2}$ Providing care within this framework results in a high level of complexity. Many challenges arise when delivering personalized, highquality care to a diverse and complex PHC population. In response to this complexity, transdisciplinary collaboration of different health professionals within clinical practice and in research is the solution.

\section{Challenges of Primary Health Care and Research}

PHC is a multidimensional concept derived from the social model of health. PHC should address the main health problem of the communities and reflect the socioeconomic, sociocultural, and political characteristics of the country it is in. ${ }^{3}$ Using this definition, providing care to one individual means not only looking at the disease of the patient, but at all elements of their life and environment.

Thus, the main challenge of PHC is meeting the unique needs of the diverse and complex clientele it has to serve. Take for example the complex issue of the optimal clinical management of an elderly patient with multiple chronic diseases living in poverty. The intertwined issues of the patient's life must be taken into account: his ability for self-management, his sociocultural environment, and his financial challenges. Take another patient: a recently immigrated healthy man with a university degree and employment in his native country before he moved, but since his arrival has been unemployed and develops symptoms of depression. It is likely that these patients' sociocultural environments have a profound impact on their health and wellbeing, and all of this has to be taken into account. These two patients have quite distinct stories, but both need to receive the personalized, high-quality care that will address the underlying causes of their health challenges.

In these two examples, what could be defined as 'effective' or 'high-quality' care? For the first patient, it might be to aim for a better quality of life in the context of his multiple chronic diseases. For the second, it might be to assist with his integration into his new environment, in order to address his depressive symptoms. Indeed, much research still needs to be done to better define what 'good' PHC is, and how to provide patient-centred care in this context of complexity. 4

\section{Transdisciplinarity and TUTOR-PHC}

Historically, a single health professional, usually the PHC physician, was tasked with managing this kind of complexity. This is changing. The research questions focussed on PHC are also changing. Providing high-quality, patient-centred care for patients requires the effective collaboration of researchers and health professionals alike. This is where transdisciplinarity comes into play. Transdisciplinarity, defined as an approach that integrates the natural, social and health sciences and in so doing, transcends each of their traditional boundaries is an ideal approach when used appropriately. ${ }^{6}$

One example of successful transdisciplinary work in research is the TUTOR-PHC (Transdisciplinary Understanding and Training on Research - Primary Health Care) program, based at Western University. ${ }^{7}$ This fellowship has two main goals: first, to build a critical mass of skilled, independent researchers and second, to increase the transdisciplinary focus in PHC research. ${ }^{6}$ This annual program selects trainees from diverse fields, including sociology, occupational therapy, nursing, health education, clinical 
psychology, social work, policy-making, epidemiology, and family medicine. Since its creation in 2003, this program has trained more than one hundred fellows through an innovative curriculum and mentorship.

One successful outcome of the TUTOR-PHC program is the Patient-Centred Innovations for Persons with Multimorbidity (PACE in MM). ${ }^{8,9}$ Recently funded by the Canadian Institutes of Health Research, this exemplary transdisciplinary collaboration in $\mathrm{PHC}$ has the mandate to improve the delivery of PHC for people with multiple chronic diseases, or multimorbidity. ${ }^{8}$ The PACE in MM team is co-led by a past TUTOR-PHC fellow and consists of twenty-one members, many of which are previous fellows or mentors of the TUTOR-PHC program. Not only will this team transform the way in which patients are managed in PHC, this work will be guided by the principles of patientcentred medicine. These are two key elements of the future of PHC.

\section{Conclusion}

The field of PHC is beautifully complex and is the cornerstone of our health care system; this is the reason each of us is drawn to it. PHC researchers and providers must challenge themselves to learn and work within a transdisciplinary environment, to go beyond their own disciplines and crumbling silos. Due to the increasing complexity of the PHC patient population or clientele, there is truly much at stake. This transdisciplinary collaboration is indeed the future of a high-quality and effective PHC system.

\section{References}

1. World Health Organization. Declaration of Alma Ata Declaration of Alma Ata [Internet]. International Conference on Primary Health Care, Alma Ata, USSR: World Health Organization; 1978 Sep 12 [cited 2014 January 10]. Available from: http://www.ncbi.nlm.nih.gov/pubmed/20505396

2. Keleher $\mathrm{H}$. Why primary health care offers a more comprehensive approach to tackling health inequities than primary care. Aust J Prim Health. 2001;7(2):57-61.

3. Thomas-MacLean R TD, Ackroyd-Stolarz S, Fortin M, Stewart M. "No cookiecutter response" Conceptualizing Primary Health Care [Internet]. [Place Unknown]: University of Western Ontario; [updated date unknown; cited 2014 Mar 6]. Available from: http://www.uwo.ca/fammed/csfm/tutorphc/documentation/trainingpapers/TUTOR_Definitio_\%20of_primar_\%20 health_care.pdf.

4. Stewart M. Towards a global definition of patient centred care. BMJ. 2001; Feb 24:322(7284):444-5.

5. Starfield B. Primary care and equity in health: The importance to effectiveness and equity of responsiveness to peoples' needs. Humanity Soc. 2009 Feb 1, 2009;33(2):56-73

6. Choi BC, Pak AW. Multidisciplinarity, interdisciplinarity and transdisciplinarity in health research, services, education and policy: 1. Definitions, objectives, and evidence of effectiveness. Clin Invest Med. 2006 Dec;29(6):351-64.

7. Stewart M, Reid G, Brown JB, Burge F, Dicenso A, Watt S, McWilliam C, Beaulieu MD, Meredith L. Development and implementation of training for interdisciplinary research in primary health care. Acad Med. 2010 Jun; 85(6): 974-979.

8. Stewart M, Fortin M. PACE in multimorbidity : Patient-Centred Innovations for Persons with Multimorbidity[Internet]. Chicoutimi, Canada: The International Research Community on Multimorbidity; 2013 [updated 2013 July 18; cited 2014 March 10]. Available from: http://crmcspl-blog. recherche.usherbrooke.ca/?page_id=248.

9. CBPHC Innovation team: Moira Stewart [Internet]. Place unknown: Canadian Institutes of Health Research; 2013 [updated 2013 Sep 03; cited 2014 March 10]. Available from: http://www.cihr-irsc.gc.ca/e/47161.html.
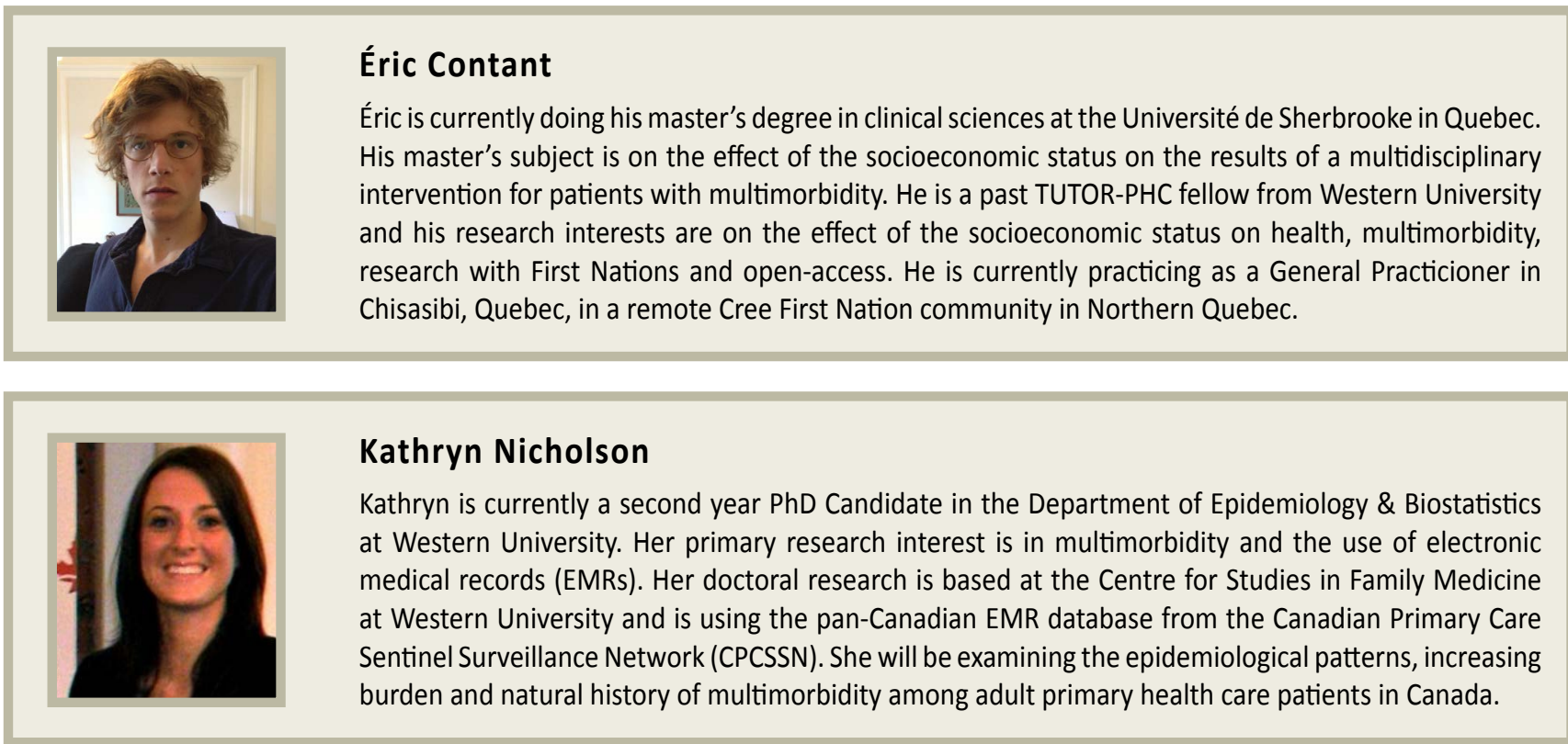